\title{
A Plea for Commonality Without Common Points -With Reference to The Planet of the Apes ${ }^{1}$
}

\author{
Junga Shin, Yong Ho Choi \\ Hankuk University of Foreign Studies, Seoul, Korea
}

\begin{abstract}
In the science fiction novel titled The Planet of the Apes (1963), Pierre Boulle tells a story about a completely reversed world where the apes dominate the humans. Coming from the normal world that is ours, a small group of people is totally embarrassed and confused by observing this strange world. On the planet of the apes that they have discovered, it is the apes that are more intelligent than the humans. On the earth, it was the other way around. That observation results in their perplexity. The two communities, human and simian, bear with one another the relationship that corresponds to what Lotman calls "enantiomorphic pairings". In this context, a series of questions deserves to be raised: Is a "common language" possible between the two communities in the enantiomorphic pairings? If the answer is yes, under what conditions could they succeed in opening up a space where they can have something in common? In rereading The Planet of the Apes with reference to Lotman's semiotics of culture, we would like to formulate a response to those questions. Our claim is that the experience of finitude of one's own language can make possible an access to the new form of universality requisite for the cross-cultural communication: commonality without common points.
\end{abstract}

Keywords: The Planet of the Apes, enantiomorphism, semiotics of culture, commonality without common points, frontier, communautarism, universalism

\section{Introduction}

What kind of community can we hope for in an era where the common sense is gravely at risk of collapse? How can we still imagine the community to come in that situation? Should a community be absolutely constructed on the basis of common points between community members? In this paper, we suggest undertaking a thought experiment the purpose of which is to explore possibilities for understanding basic conditions through which a form of commonality is constructed without any common point. In order to tackle this question, we would like to reread The Plant of the Apes by Pierre Boulle from a semiotic point of view in the following order: (1) the paradox of enantiomorphism; (2) in search of common language; (3) commonality without common points.

\footnotetext{
1 This paper is revised from the two different sources already published in French as well as in Korean: the French version published in 2014 is entitled "Pour unesémiotique de la frontière: l'émergence d'un sujetéthique-à la quête d'un senscommun"; the Korean version published in 2013 is entitled "Some issues on semiotics of culture with reference to the Planet of the Apes by Pierre Boulle". For the shake of the English version, we have slightly changed some emphasizing points with a special focus on the key concept of commonality of common point.

Junga Shin, Ph.D., French Porfssor, Department of French Studies, Hankuk University of Foreign Studies.

Yong Ho Choi, Ph.D., French Professor, Department of French Studies, Hankuk University of Foreign Studies.
} 


\section{The Paradox of Enantiomorphism}

Imagine that two cultural communities or semiospheres are in perpetual conflict with one another for some reasons. In other words, they are all intransigent about their positions. Semiotically speaking, a solid code of conduct is at work inside each of them. It functions as a very strong organizing center, which perpetually hinders one party from coming to an eventual compromise with its opposite party. In the science fiction novel titled The Planet of the Apes (1963), Pierre Boulle tells a story about the completely reversed world where the apes dominate the humans. Coming from a normal world that is like ours, a small group of people are totally embarrassed from observing this strange, i.e., abnormal world. On the planet of the apes that they have just discovered, the apes look more intelligent than the humans. On Earth, it was the other way around, of course. Their perplexity is of an essentially anthropological order. Let us say at the outset that the two societies, human and simian, hold here a relation with each other, which corresponds to what Lotman calls "enantiomorphic pairing" (Lotman, 2005, p. 225). This situation is very particular in the sense that there is no third way to fully objectify one's axiological stance vis-à-vis its opposite. The space travelers are faced with this situation on the planet of the apes.

This very particular situation can be generalized from the point of view of cultural anthropology. In his paper intitled "The Spatial Representation of Cultural Otherness", Winfried Nöth argues "What the allegedly dangerous and admirable cultures have in common", according to Todorov (Todorov, 1989, pp. 297-298) and Lotman (Lotman, 1990, pp. 132, 142), is that both appear as the inverted mirror image of one's own: "the despised carnivals are those who do things that we are not allowed to do, that the noble savages are those in whose culture things appear simple that are complex in our civilized culture" (Nöth, 2007, p. 10). What is at stake in our globalized society becoming more and more multicultural is that paradoxical logic, capable of leaving us finally trapped in an inextricable conflict. According to this logic based on enantiomorphism, what is considered to be true on one side, for instance, tends to be interpreted as being false on the other side, and vice versa. Within this context, a series of questions deserves to be raised: Is a "common language" (Lotman, 2000, p. 38) between enantiomorphic pairings possible? If the answer is yes, how can it be constructed? What might the two opposite parties have in common? In short, is commonality possible even without common points?

To deal with those questions from a culturalogical point of view, we would like to refer especially to Yuri M. Lotman who argues that:

Toute culture commence par diviser le monde en «mon» espace interne et «leur» espace externe. La manière dont cette division binaire est interprétée dépend de la typologie de la culture concernée. Mais la division véritable est celle qui provient des universaux culturels humains. (All culture begins by dividing the world into my internal space and their external space. The way this division is interpreted depends on the typology of the culture concerned. But the real division is that which comes from human cultural universals.). (Lotman, 2000, p. 38)

Enantiomorphism radicalizes this binary division to the point that all the quests for "human cultural universals" fall into impasse. In the following discussion, we would like to make a plea for what we like to call "commonality without common points" to the benefit of the possibility of a new type of universality under the context of enantiomorphism.

\section{In Search of a Common Language}

Within the framework of semiotics of culture, Lotman and Uspensky argue that "culture is never a universal set, but always a subset organized in a specific manner" (Lotman \& Uspensky, 1978, p. 211). In the 
field of culturalogy, what is universal doesn't consist of a set of characteristics that are supposed to be shared by all human cultures, simply because a culture could not but be described only in specific terms. To speak like Lacan, human culture is always constructed in the form of "pas-tout". This is to say that it can be considered as a valuable heritage only when it is limited, or specific, in other words, delimited by a certain boundary.

Semiosphere is a delimited space where the boundary plays an important role to translate unfamiliar elements coming from the outside into familiar language. The existence of a translation system supposes two types of division available in a given semiosphere: a division between the inside and the outside, on the one hand and a division between the core and the peripheries, on the other hand. If the former supposing the plurality of semiosphere is concerned with what Roman Jakobson calls "interlinguistic translation", the latter is tied to what he calls "intralinguistic translation" inasmuch as it results in different levels of translability: at the core translability reaches a high level; at the peripheries its degree remarkably diminishes. What is interesting is that enantiomorphism transforms the interlinguistic translation problem into an intralinguistic translation by excluding the possibility of an exterior.

In that paradoxical situation described in terms of enantiomorphism, all efforts to find a common language are likely to end in failure. The reason for this is pure and simple. In the system of enantiomorphic pairings, there is no room for the first type of division, i.e., a division between the inside and the outside. Enantiomorphism is a closed system that denies the existence of an exterior. In other words, any possibility of mediation does not exist between the two semiospheres concerned. For the sake of clarification, take a look at the following schema (see Figure 1):

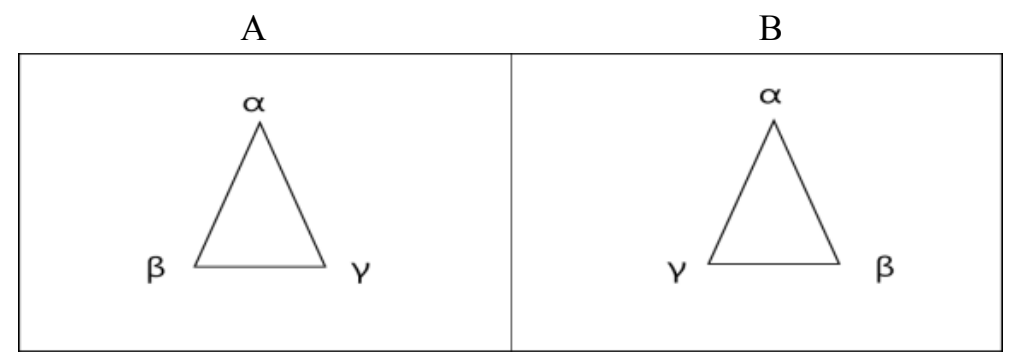

Figure 1. Enantiomorphism.

Inside a semiosphere called "A" there exists a core, represented above in the form of a triangle $\alpha, \beta, \gamma$. Different ways of living, judging, behaving, in short. All "forms of life" (Fontanille, 2008) are regulated here by that interpreting system playing the role to centralize the semiosphere, i.e., a semiotic action which $\mathrm{Ch}$. S. Peirce (1978) baptized "semiosis". In the semiophere "B", one can observe exactly the same idealogical, pragmatical, axiological structure as in the former, except that it functions in the opposite direction. Enantiomorphic pairing is thus set up between the two semiospheres "A" and "B" in such a way that the truth claim being made on one side, for instance, is translated into the falsehood on its opposite side, and vice versa. Under these conditions, how is it possible that a common language is created between the two semiotic systems? How to succeed in overcoming the limits of communitarianism? In other words, is it possible to go in search of universality? The key question is "how humanity can be constructed on the basis of the diversity of humanities" (comment construire l'humanité à partir des humanités) (Rastier \& Bouquet, 2002, p. 245).

In the story of The Planet of the Apes, what brings painful perplexity to the space travelers is a particular situation caused by enantiomorphism. In my view, attempting to give an account of their confusion exclusively 
from an evolutionary point of view prevailing all along the story seems to be beside the point, because the main reason why Ulysse's family has to escape from the planet of the apes has mainly to do with a cultural as well as political bias. This type of bias is quite common to anthropological experiences. In his book intitled Nous et les autres, Todorov clearly shows how that cultural bias can be successfully dealt with through a process of translation.

Mes deux moitiés communiquent entre elles, elles cherchent un terrain d'entente, elles traduisent l'une pour l'autre jusqu'à ce qu'elles se comprennent. L'ethnologue ne sombre pas dans le délire schizoïde parce qu'il reste à la recherche d'un sens commun, et, à la limite, universel. (My two halves are communicating with one another, looking for a common ground and translating for one another to the point that they could understand each other. The ethnologue doesn't fall into schizoid personality disorder, because he is being in quest of a common sense, further universal one.). (Todorov, 1989, $\mathrm{p}$. 123)

In the above passage, Todorov comes up with a model of intercultural translability, on the basis of which all his universalist project aimed at finding a "common ground" is established. In the matter of enantiomorphism, however, this position is hardly defendable. When referring to The Planet of the Apes, there is no doubt that the humans feel uncomfortable about the idea that the apes might be more intelligent than them not just on the planet of the apes. In other words, this awful idea can never be translated into their anthropocentric language. In short, the human being must be at the center of the universe for good. Unfortunately, the same is the case with the simian semiosphere. Now the apes feel shame about the idea that the humans have a disposition toward behaving intelligently as much as they do, even though this bizarre idea is proven to be true scientifically. For instance, in view of Zaïus, an orangutan, the human being is not but a wild animal deprived of inspiring spirituality as well as rationality. The two semiospheres, human and simian, are completely incapable of translating "for one another to the point that they could understand each other". The semiotic structure of that enantiomorphic pairing can be represented in the form of a tree as follows (see Figure 2).

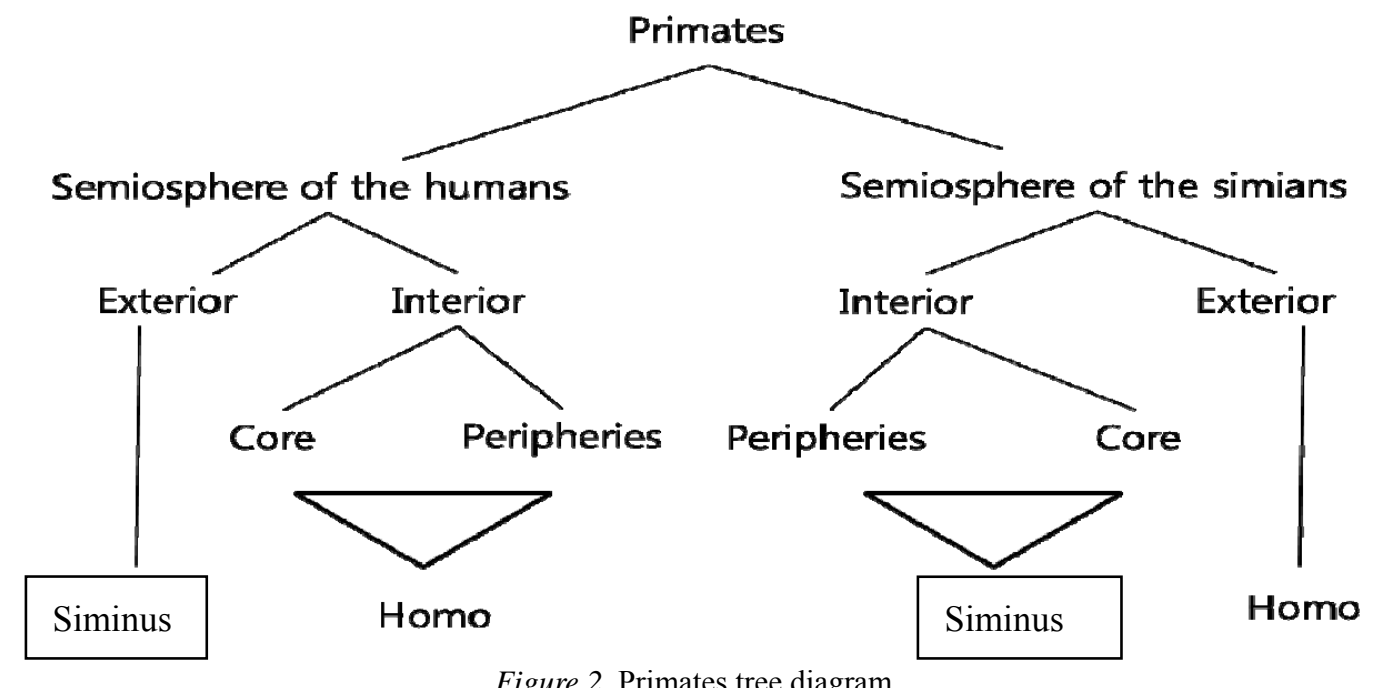

Given this situation, the possibility to find a "common ground" between the two opposite parties, i.e., Homo and Siminus, is schematically closed up. In this regard, it is interesting to see that the novel ends up in the complete disappearance of the human civilization as well as in the simian domination of the whole universe. 
The conflict between the two semiospheres fades away as the humans give way to the apes. As a consequence, the only one semiosphere prevails all over the universe. The picture of this state of affairs can be drawn as follows (see Figure 3):

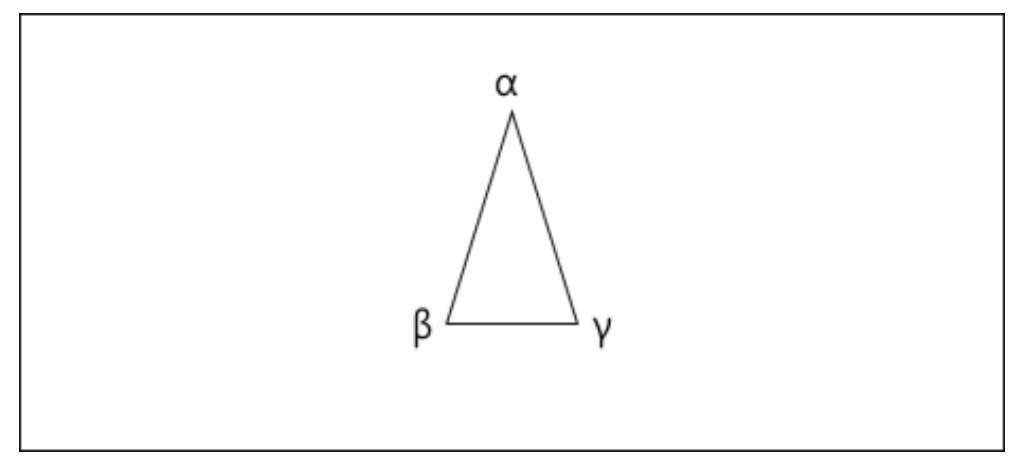

Figure 3. The semiosphere.

Notice that the above schema shows only one semiosphere, i.e., the semiosphere where there is only one core. The two types of division are thus totally neutralized. If one can speak of universality in that situation, it's only a universality imposed by the logic of natural selection, i.e., a logic of power.

As seen above, it is due to the fundamental incompatibility constitutive of the enantiomorphism that all efforts to discover a "common ground" between the two semiospheres in conflict bump into a barrier as long as enantiomorphic pairings persist. A question arises imperatively how to break up this vicious circle without having recourse to the logic of power. In my view, there seems to be only one solution. To make a long story short, the solution of that question consists in disclosing the exterior excluded by the enantiomorphic system. Hence the following schema (see Figure 4).

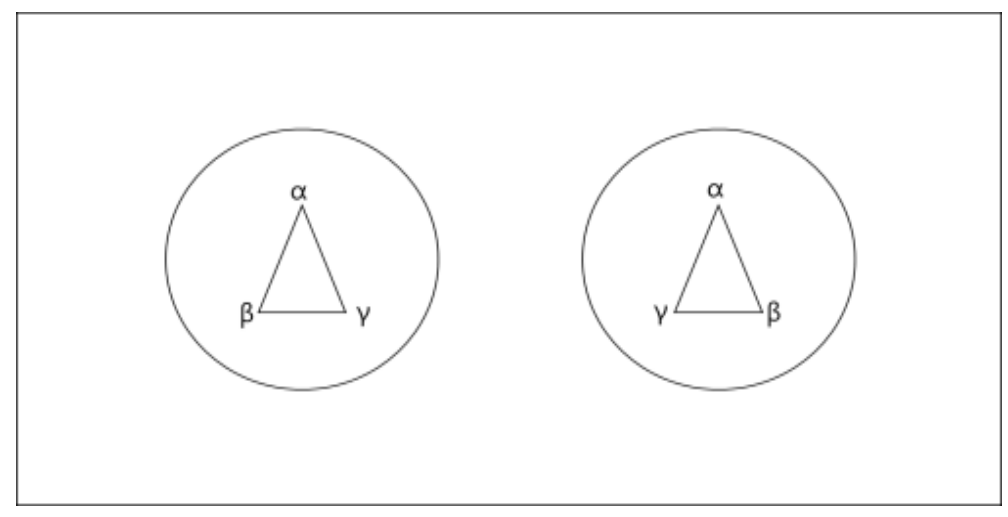

Figure 4. Enantiomorphic semiotic system.

Take an example, the novel begins with a letter of plea, Ulysse sends out in outer space to sound an alarm, crying out that the whole of humanity is being at risk of extinction. This is to say that the totality of the human semiosphere is exposed to its extreme limits.

I am confiding this manuscript to space not with the intention of saving myself, but to help, perhaps, to avert the appalling scourge that is menacing the human race. Lord have pity on us! ... (Boulle, 1963/1993, p. 9)

Interestingly, the same thing happens on the planet of the apes. When the apes find out that Ulysse has incredible capabilities of reasoning as well as speaking, the solid faith in the totality of their semiosphere begins 
to be cracked. Hence the following reaction from the apes:

The orangutans hate you because you are the living proof of their scientific aberrations, and the gorillas consider you too dangerous to be allowed at liberty much longer. They are frightened you might found a new race on this planet. But apart from this eventuality, they are frightened that your mere example might sow unrest among the men. Unusual nervousness has been reported among the ones with whom you are dealing. (Boulle, 1963/1993, p. 256)

For the sake of clarification, take a look at the following semiotic square based on the logico-semantic relations of contrariness (Homo vs. Siminus) and contradiction (Homo vs. - Homo; Siminus vs. - Siminus) (see Figure 5).

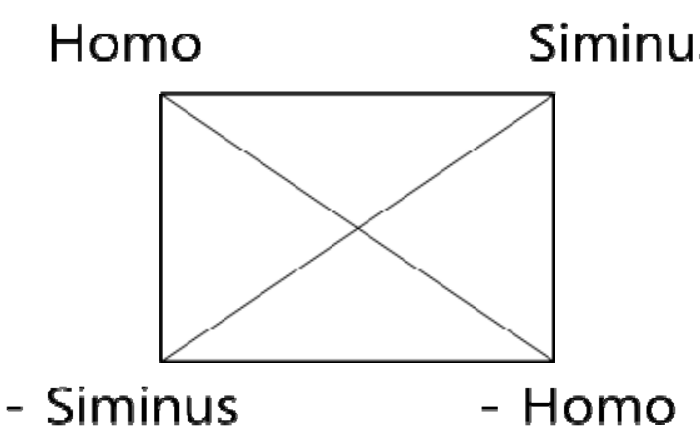

Figure 5. Semiotic square of Sapiens.

According to a structural tenet, all semiotic systems are firmly established due to the oppositional relationship between at least two terms A and B, for instance. If Ulysse's family has to escape from the planet of the apes, it is because the complex term combining A (Homo) and B (Siminus) is not possible in the enantiomorphic system. However, notice that when those two terms are denied at the same time, surprisingly, the systematicity of the opposition-based semiotic system is radically called into doubt so that this system cannot sustain itself anymore. It is at this critical moment defined by the complex term linking - B (- Siminus) with - A (- Homo) that the emantiomorphic system begins to crack down. Let me represent that process of collapsing with the dotted line as follows (see Figure 6).

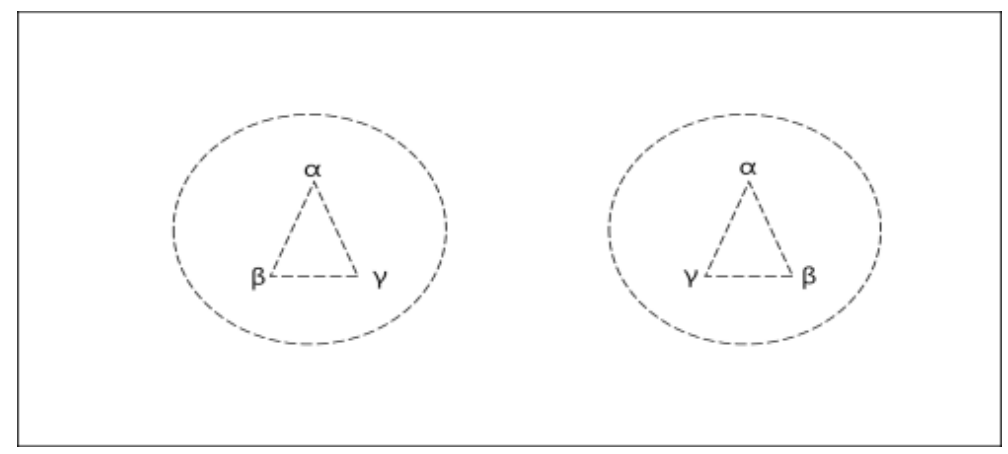

Figure 6. Enantiomorphic semiotic system collapse.

The limits of enantiomorphism happens to be unveiled little by little through a process we would like to call double crossed contradiction, characterized in terms of neither A nor B. It is interesting to observe how Ulysse goes through this critical moment. Just after the congress where he has successfully demonstrated his capability as a rational being, he has this bizarre feeling at a party organized by his ape friends in order to 
launch him into simian society.

The confusion was caused by the alcohol that I started swilling as soon as I arrived, and to which my system was no longer accustomed. The disturbing effect was an odd sensation that was to come over me on many other occasions. I can only describe it by saying that the nature of the figures around me became progressively less simian, whereas their function or the position they held in society became dominant. The head waiter, for instance, who came up obsequiously to show us our table, I saw only as the head waiter, and the fact that he was a gorilla tended to be obscured. The figure of an elderly she-ape with an outrageously painted face was replaced by that of an old coquette, and when I dance with Zira I forgot her condition completely, and my arm merely encircled the waist of a dancer. The chimpanzee orchestra was nothing more than an orchestra, and the elegant apes exchanging witticisms all around me were simply men about town. (Boulle, 1963/1993, p. 183)

The illusion described above is not simply caused by the alcohol. Being part of simian community, Ulysse begins to focus not on the race of those he meets but on their social function or position. It seems that neither human nor simian makes any sense to him.

Alain Badiou attempts to account for the foundation of a Christian discourse, relying on such a double crossed contradiction as neither Greek discourse nor Jewish discourse. According to him, it is only through this gesture of double rejection that Saint Paul makes a claim for universal truth, which can be summed up as follows: "there is neither Jew nor Greek, there is neither slave nor free man, there is neither female nor male". Let me just add to this adage "neither Homo nor Siminus".

\section{Commonality Without Common Points}

Our working hypothesis is that when the two semiospheres in conflict are deterritorialized at the same time, an opportunity opens up to create a common ground. The type of universality we would like to defend here does not reside in the intersection space between those two semiospheres. It resides rather in the space of complementariness where one cannot claim its own validity vis-à-vis its opposite. It is interesting to note that where the two semiotic systems based on enantiomorphism are suspended at the same time, the part which has been invisible in the background begins to make itself visible, as illustrated in the above schema. Our claim is that this is just what happens when Ulysse moves from the earth to the planet of the apes, from one semiosphere to another. In other words, he cannot cross over the borderline between the two semiospheres without casting doubt at the same time on the consistency of each of the semiotic systems he refers to for the sake of understanding the world he is traveling around. In the course of this so-called inter-semiospheric movement, a background, which has been dissimulated until then, is open. It is in this background that we would like to spot the possibility of a new type of universality. By the latter, we mean "commonality without common points".

According to Kant, all forms of value judgment are based on sensus communis. The interpretation system in a given semiosphere functions with reference to this sense of community. To successfully establish a universal community in the Kantian sense of the word, this sensus communis, in my view, must be among the first to be questioned. From that moment on, it becomes possible to go beyond the limits of communitarianism in search of another sense of community aimed at universality. For instance, in The Planet of the Apes, a female monkey called Zira and a male human called Ulysse develop feelings for each other. And a significant change occurs with respect to their sensus communis. That is to say, they attempt to exceed altogether the limits of communitarianism. Knowing that if she helps Ulysee to escape from the planet, she has to pay a huge price for her disobedience, Zira takes a risk. She has the courage to transgress the sensus communis of the simian 
semiosphere she belongs to. As for Ulysse, he expresses his heart felt gratitude for Zira as he is little by little attracted to her personality. This change is well illustrated by the scene where they learn each other's language. Zira teaches Ulysse the Simian language and Ulysse teaches Zira the French language.

From then on, thanks to Zira, my knowledge of the simian world and language increased rapidly. She contrived to see me alone almost every day on the pretext of some test and undertook my education, instructing me in the language and at the same time learning mine with a rapidity that amazed me. In less than two months we were capable of holding a conversation on a variety of subjects. (Boulle, 1963/1993, p. 125)

However, they have some difficulties understanding, for instance, two words, i.e., "ape" and "man". These two words refer to the same things but mean different things. But they overcome those difficulties by opening up a very specific translation space of neither Simian language nor French language. At the end of the story, their kiss scene dramatically shows how a universal community between them can be established even for a short period of time.

I stop and take her in my arms. She is as upset as I am. I see a tear coursing down her muzzle while we stand locked in a tight embrace. Ah, what matter this horrid material exterior! It is her soul that communes with mine. I shut my eyes so as not to see her grotesque face, made uglier still by emotion. I feel her shapeless body tremble against mine. I force myself to rub my cheek against hers. We are about to kiss like lovers when she gives an instinctive start and thrusts me away violently. (Boulle, 1963/1993, p. 260)

Of course, there is nothing that a female ape has to share with a male man. But the Siminus Sapiens called "Zira" has a desire to get close to the Homo Sapiens called "Ulysse" and to share something with him. So they have learnt each other's languages. They feel together a sense of belonging without actually belonging to any community, neither Homo nor Siminus. At this moment, what we would like to propose calling communality without common points begins to take form and shape between the two Sapiens. In this community the sensus communis doesn't cease to be questioned to the benefit of a new form of life. That's why we have to start again where the story ends.

\section{Conclusion}

Our conclusion can be summed up as follows:

(1) The world system becomes more and more enantiomorphic, which means that a semiotic system (or a semiosphere) is being closed up without there being any further need to communicate with others;

(2) In that situation, the double deterritorialization, which, according to Badiou, can be expressed in terms of "neither... nor" can open up a space where the closed system breaks down and the quest for a new commonality can be started off;

(3) That space can be characterized as a "political" space of our era.

\section{References}

Badiou, A. (1998). Saint Paul: La fondation de l'universalisme (Saint Paul: The foundation of the universalism). Paris: Puf. Benjamin, W. (1916/1997). On language as such and on the language of man. In M. Bullok and M. W. Jennings (Eds.), Selected writings V. 1 1913-1923. Cambridge, Massachutts, London, England: The Belknap Press of Havard University Press.

Boulle, P. (1963/1993). La planète des singes (The planet of the apes). Paris: French \& European Pubns.

Fontanille, J. (2008). Pratiques sémiotiques (Semiotic practices). Paris: Puf.

Kant, E. (2000). Critique de la faculté de juger (The cirtique of judgment). Paris: Flammarion.

Lotman, J. M. (2005). On the semiosphere. Sign System Studies, 33, 1. 
Lotman, J. M. (2004). L'explosion et la culture (Culture and explosion). Paris: Pulim.

Lotman, J. M. (1990). Universe of the mind: A semiotic theory of culture. London \& New York: I. B. Tauris \& Co. Ltd.

Lotman, J. M. (2000). La sémiosphère. Nouveaux actes sémiotiques (The semiosphre). Limoges: PUL.

Lotman, J. M., \& Uspensky B. A. (1978). On the semiotic mechanism of culture. New Library History, 9(2). Baltimore: The John Hopkins University Press.

Nöth, W. (2007). The spatial representation of cultural otherness. In S. K. Gertz, J. Valsiner, and J. P. Breaux (Eds.), Semiotic rotations: Modes of meanings in cultural worlds. NC: Charlotte.

Peirce, Ch. S. (1978). Ecrts sur le signe (Writings on the sign). Paris: Puf.

Rastier, F., \& Bouquet, S. (2002). Une introduction aux sciences de la culture (An intorduction to the sciences of culture). Paris: Puf.

Shin, J., \& Choi, Y. H. (2013). On trans-semiosis. Semiotica, 193.

Todorov, T. (1989). Nous et les autres (We and the others). Paris: Edition du Seuil. 